Thorax (1966), 21, 385.

\title{
Closed-chest circulatory support by pump-oxygenator in experimental ventricular fibrillation at normal temperature
}

\author{
E. P R O T O R
}

From the Thoracic Research Department, Guy's Hospital, London S.E.I

Interest is growing in the use of closed-chest circulatory support via peripheral cannulation, using pumps or pump-oxygenators, both in emergencies encountered during the post-operative period following intracardiac surgery (Spencer, Eiseman, Trinkle, and Rossi, 1965) and electively in intracranial surgery using profound hypothermia and cardiac arrest (Woodhall, Sealy, Hall, and Floyd, 1960 ; Michenfelder, Kirklin, Uihlein, Svien, and MacCarty, 1964). However, the use of a pump-oxygenator to provide circulatory support in non-surgical cardiopulmonary emergencies such as acute myocardial infarction with shock is still rarely exploited in spite of the early work of Stuckey, Newman, Dennis, Berg, Goodman, Fries, Karlson, Blumenfeld, Weitzner, Binder, and Winston (1957).

There is some justification for this neglect. Experimentally, Ross, Gilbert, Sharp, and Morrow (1958) in the open-chest animal, and more recently Patterson and Ray (1962) and Johnston, Nield, Pritchard, and Hercus (1965) in the closedchest animal, have pointed to the danger of high left atrial pressures developing during venoarterial bypass in the presence of cardiac arrest or acute left heart failure, due to the accumulating inflow of pulmonary, bronchial, and thebesian blood into the left heart. The left atrial pressure was more likely to rise if it was already high at the start of bypass (a strong possibility in acute left heart failure), and also if the circulatory support flow rate was high (as it may need to be at normal temperature if a reduction in the work load and oxygen consumption of the myocardium is desired (Salisbury, Bor, Lewin, and Rieben, 1959 ; Schenk, Delin, Camp, McDonald, Pollock, Gage, and Chardack, 1964) ). There would be little point in raising the systemic arterial pressure and increasing the coronary flow if pulmonary oedema and acute distension of the left heart resulted.
It is therefore important to determine the effect of total circulatory support on the left atrial pressure in the closed-chest animal at normal temperature, in the presence of a failing left ventricle or cardiac arrest, before contemplating such support clinically in acute myocardial infarction.

From preliminary studies in the closed-chest animal it was known that more than $90 \%$ of the circulating blood volume could be diverted to the pump-oxygenator at normal temperature for up to 10 hours with survival. Furthermore, it was known that, in acute left heart failure and ventricular fibrillation induced by coronary artery ligation in the open-chest animal, total circulatory support by peripheral cannulation and pumpoxygenator could markedly benefit the majority of the hearts while maintaining safe levels of left atrial pressure (Proctor and Kowalik, 1966). The point at issue was whether the conditions under which the technique would be used clinically (in the closed chest with negative intrathoracic pressure, and little practical chance of draining the left atrium) would affect the left atrial and pulmonary pressures, particularly in the presence of a non-functioning heart.

\section{METHOD}

The experiments were performed on 12 mongrel dogs weighing 16 to $27 \mathrm{~kg}$. After premedication with morphine, 10-15 mg., and atropine, 0.3 mg., intramuscularly, anaesthesia was induced with intravenous thiopentone sodium, the trachea was intubated, and anaesthesia was maintained with halothane and oxygen using a Starling type respirator. Arterial pressures and blood gas samples were obtained from the abdominal aorta via a catheter in the right femoral artery. Venous pressures were obtained through a catheter introduced into the axillary vein by way of the right brachial vein. Left atrial pressures were obtained in one group using a catheter placed in the left atrium before closure of a limited left thora- 
cotomy, and in the other group by trans-bronchial puncture (Henschel, Hamilton, and Rainbow, 1957). Electrocardiograms were taken on all animals. Temperatures were measured in the pharynx and in the reservoir of the pump-oxygenator.

To avoid the problems associated with the use of homologous blood in dogs (Gadboys, Jones, Slonim, Wisoff, and Litwak, 1963), circulatory support was carried out with a pump-oxygenator of our own design (Proctor and De Bono, 1965), in which total bypass can be initiated and maintained for up to two hours with a priming volume of $750 \mathrm{ml}$. of Ringerlactate and low molecular weight dextran ; 50 to 100 $\mathrm{ml}$. of Ringer-lactate is added for each hour beyond this to compensate for urinary, metabolic, and respiratory losses. When on total bypass, flow rates were of the order of 2 to $2.41 . / \mathrm{min} . / \mathrm{m}^{2}$ Venous connexions for the peripheral bypass were made with a long, thin-walled catheter inserted through the left femoral vein to the level of the right atrium; a single catheter was always sufficient. For smaller dogs with flows of the order of $1.61 . / \mathrm{min}$. a polypropylene catheter of $4.9 \mathrm{~mm}$. internal diameter and $6.0 \mathrm{~mm}$. external diameter was used; for larger dogs with flows up to $2.51 . / \mathrm{min}$. a polythene catheter of 5.5 $\mathrm{mm}$. internal diameter and $7.8 \mathrm{~mm}$. external diameter was sufficient to ensure a full venous return. Arterialized blood was returned to the animal using a short stainless steel cannula in the left femoral artery. The temperature of the animals was maintained at 36 to $37^{\circ} \mathrm{C}$. during circulatory support.

A non-functioning heart was produced by external ventricular fibrillation. After $30 \mathrm{mg}$. of succinylcholine had been given intravenously, electrodes were applied to opposite sides of the shaved chest, and a single shock of 100 volts was given for 2 to 3 seconds. Defibrillation was accomplished in the same way using one to three shocks of 750 volts and $0 \cdot 1 \mathrm{sec}$. duration. In the early experiments circulatory support was begun after ventricular fibrillation had been induced, but in most of the experiments described here the animal was on partial bypass before ventricular fibrillation was induced. In this way more information could be gathered concerning the amount of circulatory support achieved in the presence of a beating heart. It was also possible to rewarm from the mildly hypothermic state $\left(34\right.$ to $35^{\circ}$ C.) usually attained by these small animals during anaesthesia and preliminary surgery to the $37^{\circ} \mathrm{C}$. expected clinically.

The animals were divided into two groups:

GROUP 1 Six animals underwent a limited left thoracotomy with cannulation of the left atrium and closure of the thoracotomy over a chest drain. These acted as a link with a previous open series and were used to study the effect of changes in intrathoracic pressure on the left atrial pressure during circulatory support. Three of these animals also had the left atrial pressure measured simultaneously by the transbronchial route as a check on the validity of the procedure under these conditions.
GROUP 2 Six animals received no thoracotomy, and the left atrial pressure was measured by transbronchial puncture only.

Circulatory support was for a period of two hours in all cases.

\section{RESULTS}

VENTRICULAR FIBRILLATION This was consistently produced in the closed-chest animal provided that the 100-volt shock had a duration of not less than 2 seconds. A typical example of the effect of externally induced ventricular fibrillation on the systemic arterial pressure during closed-chest

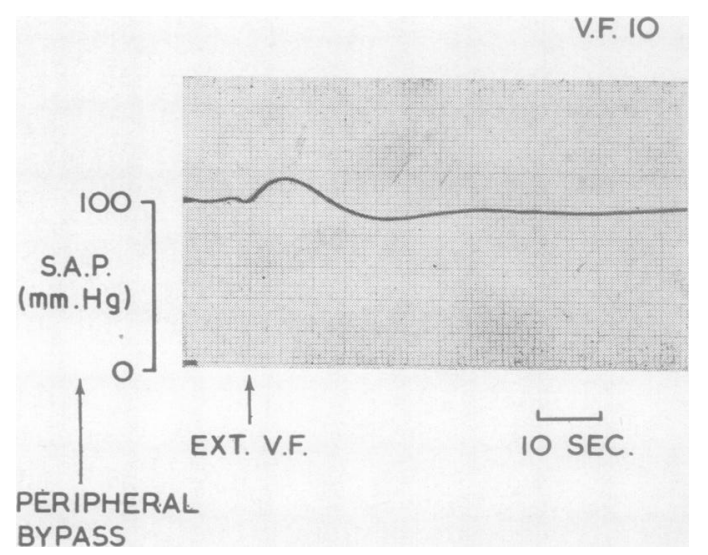

FIG. 1. A typical example of the effect of externally induced ventricular fibrillation (Ext.V.F.) on the systemic arterial pressure (S.A.P.) in closed-chest circulatory support by peripheral cannulation at $37^{\circ} \mathrm{C}$. Apart from the transient rise associated with the actual 3-sec. 100-volt shock there is no significant change in S.A.P., which, in association with an unchanged flow rate, indicated virtual total bypass before fibrillation.

circulatory support by peripheral cannulation can be seen in Figure 1. Apart from the transient rise associated with the actual shock the mean systemic arterial pressure is virtually unchanged. Figure 2 illustrates the whole information gained during one of these experiments (V.F. 10). It can be seen that there is no significant change in arterial pressure, left atrial pressure, or flow rate on induction of ventricular fibrillation. This indicates that circulatory support before ventricular fibrillation was total. However, as the error in our flow measurement is $\pm 3 \%$ it is not proven above $97 \%$.

LeFT ATRIal PRESSURe Although Figs 1 and 2 are typical of the pattern of response encountered throughout the whole study, the left atrial pres- 


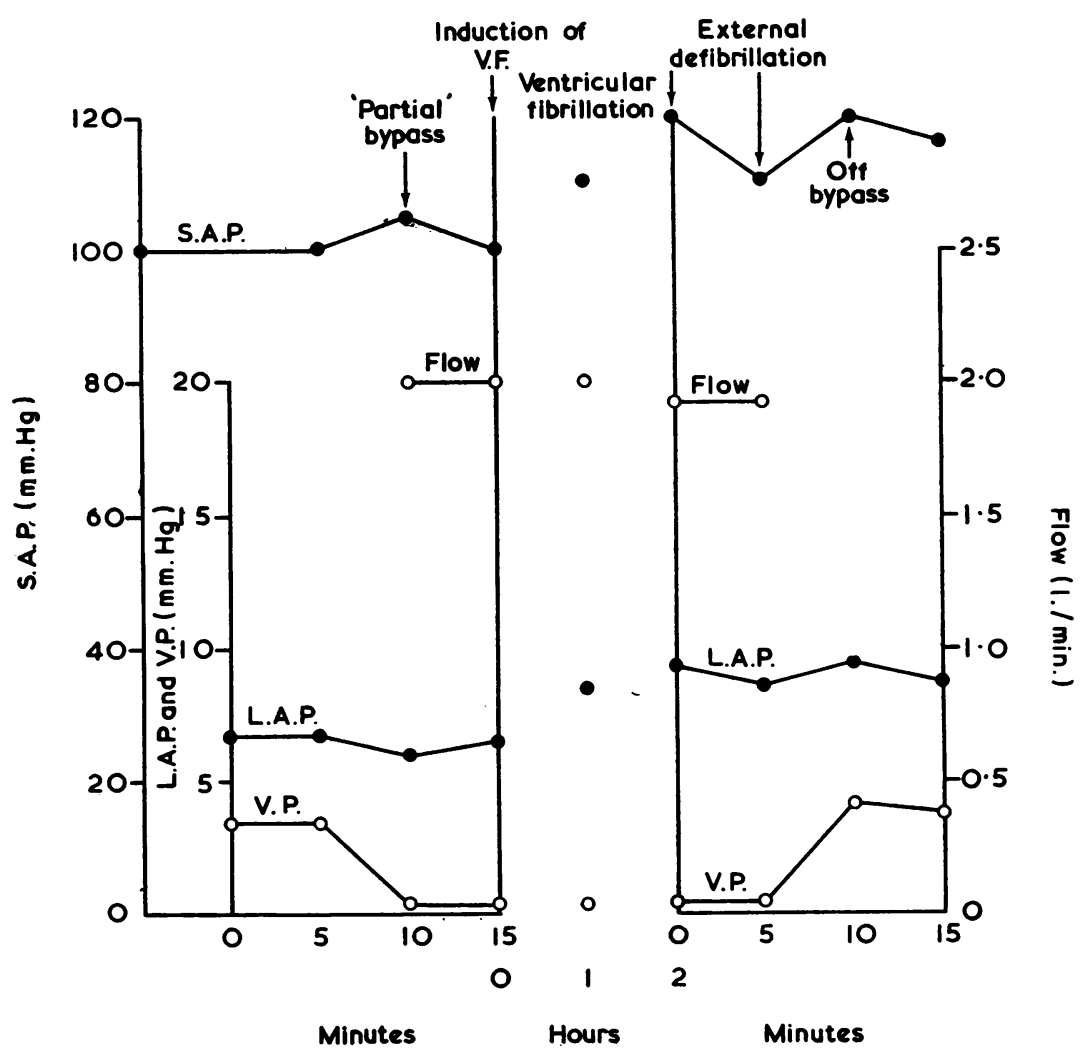

FIG. 2. Typical pattern of response to ventricular fibrillation, as illustrated by dog $V . F .10$. Values of mean systemic arterial pressure (S.A.P.), left atrial pressure (L.A.P.), venous pressure (V.P.), and flow-on partial bypass; during two-hour period of externally induced ventricular fibrillation; and after external de-fibrillation-during closed-chest circulatory support via peripheral cannulation, at $37^{\circ} \mathrm{C}$.

sures are sufficiently important to be shown separately (Table I). There is no significant difference in the left atrial pressure either pre-bypass, on 'partial' bypass, or on total bypass (ventricular fibrillation). A feature not shown in the Table

T A B L E

EFFECT OF CLOSED-CHEST CIRCULATORY SUPPORT ON THE LEFT ATRIAL PRESSURE (mm. $\mathrm{Hg}$ )

\begin{tabular}{c|c|c|c|c|c}
\hline Group & $\begin{array}{c}\text { Pre- } \\
\text { bypass }\end{array}$ & $\begin{array}{c}\text { 'Partial' } \\
\text { Bypass }\end{array}$ & $\begin{array}{c}\text { Externally } \\
\text { Induced } \\
\text { V.F. }\end{array}$ & 2 Hours & $\begin{array}{c}\text { Post- } \\
\text { bypass }\end{array}$ \\
\hline 1 & $9(4-13)^{1}$ & $6(4-14)$ & $7(3-15)$ & $8(6-12)$ & $7(4-11)$ \\
\hline 2 & $8(5-12)$ & $7(4-14)$ & $9(2-14)$ & $8(4-12)$ & $6(3-10)$ \\
\hline
\end{tabular}

V.F. = ventricular fibrillation. Flow rate $90-100 \mathrm{ml} . / \mathrm{kg}$.

Group 1: thoracotomy with direct cannulation of left atrium and closure of thoracotomy over chest drain.

Group 2: no thoracotomy and left atrial pressure obtained by transbronchial puncture.

1 The open figures represent the mean left atrial pressure in each group, and the figures in parentheses the range within each group. is that during the brief periods of re-warming used to maintain normothermia the left atrial pressure usually rose 3 to $4 \mathrm{~mm}$. $\mathrm{Hg}$ and then returned to the original level after re-warming was stopped. It is not known whether this was due to the slight increase in flow associated with re-warming, or to increased bronchial flow, or to vasoconstriction in the pulmonary vessels reducing the retrograde flow.

There was no significant difference between the the group which had the chest opened and then closed over a chest drain, and the group with no thoracotomy and measurement of the left atrial pressure by trans-bronchial puncture.

CHANGES IN INTRATHORACIC PRESSURE In group 1 two variables were controlled. The intrathoracic pressure was varied from atmospheric (chest drain open) to $40 \mathrm{~mm}$. $\mathrm{Hg}$ of vacuum, both with and 
without inflation of the lungs. The mean left atrial pressure at $40 \mathrm{~mm}$. $\mathrm{Hg}$ was $3 \mathrm{~mm}$. $\mathrm{Hg}$ lower than at atmospheric pressure. Inflation of the lungs on the respirator increased the left atrial pressure by a mean amount of $3 \mathrm{~mm}$. $\mathrm{Hg}$.

pH AND BLOOD GASES Mean values (and range) at the end of two hours' circulatory support in the presence of ventricular fibrillation at $37^{\circ} \mathrm{C}$. were : pH 7.44 (7.35-7.47); $\mathrm{PcO}_{2} 43 \mathrm{~mm}$. $\mathrm{Hg}(29-50)$; oxygen saturation (venous) $69 \% \quad(67-72 \%)$; plasma bicarbonate $22 \mathrm{mEq} / 1$. (20-25). Values during spontaneous respiration in the recovery phase were within the normal range.

There appears to be no obvious pulmonary or metabolic disturbance associated with total circulatory support in the closed chest at $37^{\circ}$ C.- at least if the perfusion conditions discussed later are adhered to.

PARTIAL CIRCULATORY SUPPORT This term is used here in the sense of circulatory support while the heart is still beating and thus capable of competing with the pump-oxygenator for the venous return. It may well be a purely arbitrary term since it is our experience both in this series and in an earlier open-chest study that the measured parameters of arterial pressure, venous pressure, and flow through the pump-oxygenator often do not change on the induction of ventricular fibrillation.

If the peak flow during the first 15 minutes of ventricular fibrillation is taken as $100 \%$ then the mean flow, in both groups, on 'partial' circulatory support immediately prior to fibrillation was $95 \%$, with a range of 88 to $104 \%$. In seven animals there was no measurable change in flow through the pump-oxygenator on induction of fibrillation ; in three there was an increase, and in two there was a decrease in flow.

SURVIVAL To eliminate factors not directly due to the circulatory support, only animals in group 1 (without thoracotomy) were allowed to recover. Five animals quickly recovered and showed no evidence of pulmonary damage either in life or at necropsy one week later; one animal died within three hours of defibrillation, and at necropsy a large amount of blood was found to have leaked from the bronchial puncture into the bronchi. As the measured parameters of the nonsurvivor were within the range of the survivors at the time of defibrillation it is felt that its death was more likely to have been due to this technical accident than to the circulatory support.
MECHANISM OF DECOMPRESSION OF THE LEFT ATRIUM Confirmation was sought for the suggestion of Ross et al. (1958) that, in the open chest during cardiac arrest, the left atrium could be decompressed through the right atrium via the pulmonary vessels and the incompetent pulmonary valve. To this end the following observations were made :

(a) During circulatory support with the heart in ventricular fibrillation the pulmonary artery was occluded by a clamp. Over a period of 20 minutes the left atrial pressure rose from 10 to $20 \mathrm{~mm}$. Hg. One minute after release of the clamp the left atrial pressure had fallen to $13 \mathrm{~mm}$. $\mathrm{Hg}$, and after three minutes to $11 \mathrm{~mm}$. $\mathrm{Hg}$. The same sequence occurred in the other five open-chest animals-a slow rise on occlusion of the pulmonary artery followed by a more rapid fall on release of the obstruction.

(b) A $3 \mathrm{~mm}$. internal diameter catheter was inserted through the pulmonary valve and the pulmonary artery was snugged proximal to the tip of the catheter. This catheter was sufficient to decompress the left atrium (the pressure of which was maintained at 9 to $11 \mathrm{~mm}$. $\mathrm{Hg}$ ) and also to allow collection of the retrograde flow. The mean blood flow through the catheter necessary to maintain the left atrial pressure at 9 to $11 \mathrm{~mm}$. $\mathrm{Hg}$ was 0.9 to $1 \cdot 1 \%$ of the total circulatory support flow at the time. This approximates to the expected bronchial artery flow of 0.5 to $1.0 \%$ (Salisbury, Weil, and State, 1957) plus an unknown amount due to the very small thebesian flow from the left heart. The mean systemic arterial pressure during this manœuvre was $100 \mathrm{~mm}$. $\mathbf{H g}$.

(c) Reducing the aortic pressure to $50 \mathrm{~mm} . \mathrm{Hg}$ and increasing the venous pressure from zero to $15 \mathrm{~mm}$. $\mathrm{Hg}$ by decreasing the venous return to the pump-oxygenator caused a rise in the left atrial pressure from 9 to $16 \mathrm{~mm}$. $\mathrm{Hg}$.

In the normal animal the main determinant of bronchial flow is the mean aortic pressure, but the importance of the venous pressure in the control of the left atrial pressure under these conditions of circulatory support and cardiac arrest can be judged from the fact that, in spite of a $50 \%$ decrease in mean aortic pressure-and presumably bronchial flow, the left atrial pressure increased to match the venous pressure.

(d) If sufficient Ringer-lactate $(300$ to $500 \mathrm{ml}$.) was added to raise the flow from $90 \mathrm{ml} . / \mathrm{kg}$. to $120 \mathrm{ml} . / \mathrm{kg}$., the left atrial pressure rose to a mean of $19 \mathrm{~mm}$. $\mathrm{Hg}$ and the venous pressure to $5 \mathrm{~mm}$. $\mathrm{Hg}$. 


\section{DISCUSSION}

The above studies show that, in closed-chest dogs, veno-arterial bypass using a pumpoxygenator and peripheral cannulation is capable of total circulatory support for two hours at $37^{\circ}$ $C$. in the presence of a non-functioning heart, without raising the left atrial pressure beyond safe limits, if certain conditions are maintained. These are: (1) The venous pressure must be kept low $(-1$ to $+1 \mathrm{~mm}$. $\mathrm{Hg}$ ) by adequate cannulation and suction (in this case by gravity drainage of $60 \mathrm{~cm}$.) ; (2) the animal must remain, as far as possible, isovolaemic in relation to its circulating blood volume, since an increase in the blood volume caused by a relatively small overtransfusion caused a marked increase in the left atrial pressure in spite of all other factors - except venous pressure-being kept constant. It should be noted that the pump-oxygenator used in this study, by virtue of not requiring homologous blood, did not significantly alter the animal's blood volume, one indication being that the circulating blood in the oxygenator remained within $\pm 100 \mathrm{ml}$. of the original priming volume of 750 $\mathrm{ml}$. and required no additional fluid for the first one to two hours while maintaining normal haemodynamic values.

The suggestion of Ross et al. (1958) that, in open-chest animals, the left atrium can be decompressed via a right atriotomy, is confirmed in relation to circulatory support by peripheral cannulation. A rise in venous pressure of $5 \mathrm{~mm}$. $\mathrm{Hg}$ was sufficient to abolish the small pressure gradient between the left and right atria necessary to allow the retrograde flow of up to $20 \mathrm{ml}$. $/ \mathrm{min}$. derived mainly from the bronchial arteries. When the pulmonary artery was occluded the observation that the left atrial pressure rose so slowly (from $10 \mathrm{~mm}$. $\mathrm{Hg}$ to $20 \mathrm{~mm}$. $\mathrm{Hg}$ in up to 20 minutes) is probably accounted for by the capacity of the pulmonary vessels which, at an inflow of only $20 \mathrm{ml} . / \mathrm{min}$., could delay the rise in left atrial pressure.

The further observation of Ross et al. that, if the left atrial pressure was high at the onset of bypass, it would of ten prevent a retrograde flow by closing the pulmonary valve, was not found in this series when the left atrial pressure was allowed to rise, nor in a previous series where acute left heart failure with high left atrial pressures was induced by coronary artery ligation before bypass.

The mean figure of $95 \%$ of total bypass that occurs even when the heart is beating confirms the findings of an earlier larger series of openchest, peripheral bypasses. This runs counter to the observations of Salisbury et al. (1959) that in the closed chest one could not expect to carry more than $50 \%$ of the total systemic flow on the pump-oxygenator. However, this series is not strictly comparable, since they were using 2,000 $\mathrm{ml}$. of homologous blood to prime the pumpoxygenator, and the major changes in circulatory haemodynamics demonstrated by Gadboys et al. (1963) associated with the use of homologous blood may have altered the conditions.

In the light of such a high 'partial' bypass it is not surprising that induction of ventricular fibrillation caused little change in systemic arterial pressure, left atrial pressure, and flow. This is encouraging in relation to peripheral circulatory support for acute myocardial infarction with severe shock.

Maintaining a good systemic arterial pressure with fully oxygenated blood at a normal $p \mathrm{H}$ by means of a peripheral bypass has been shown experimentally (Proctor and Kowalik, 1966) to be sufficient in itself to tide the heart over the insult of a major coronary artery occlusion, and it might be assumed that diverting all but $5 \%$ of the venous return from the heart and reducing its 'external' work would be an important factor in this procedure. However, Salisbury et al. (1959) and Schenk et al. (1964) have shown that there is no linear relationship between 'external' work done by the heart and myocardial oxygen consumption and 'internal' work load. Their results indicate that cardiac output must be reduced to zero before myocardial oxygen consumption is consistently reduced. Thus to achieve the additional benefit of a reduction in metabolic demand by the myocardium it would be necessary to divert $100 \%$ of the cardiac output to the pumpoxygenator, and to do this consistently might require the induction of ventricular fibrillation. Ventricular fibrillation itself would reduce the metabolism of the heart and increase the coronary flow, but the results of this study do not permit one to predict whether a failing heart would ever justify such a drastic manœuvre in order to obtain maximum benefit from circulatory support.

\section{SUMMARY}

Total circulatory support was carried out for two hours at $37^{\circ} \mathrm{C}$. in 12 closed-chest dogs after the external induction of ventricular fibrillation. The circulatory support was by veno-arterial bypass using a bloodless prime pump-oxygenator 
and peripheral cannulation via one femoral artery and vein. Systemic blood-pressure and blood gases were maintained within normal limits. Left atrial pressure, measured either by trans-bronchial puncture or after a limited thoracotomy, was maintained in the safe range of 5 to $15 \mathrm{~mm}$. $\mathrm{Hg}$. Changes in intrathoracic pressure from $40 \mathrm{~mm}$. $\mathrm{Hg}$ vacuum to atmospheric pressure during total circulatory support had little significant effect on the left atrial pressure.

External defibrillation was easily achieved after two hours' circulatory support, and of six animals allowed to recover five survived and one died as a result of a technical accident.

Mean partial bypass values of $95 \%$ were obtained in the presence of the beating heart before the induction of ventricular fibrillation.

The factors involved in maintaining a safe level of left atrial pressure under these conditions were ascertained.

There appears to be no insoluble problem in the use of the technique of closed-chest, venoarterial bypass by peripheral cannulation in acute myocardial infarction with severe shock or cardiac arrest, the more so now that an emergency pumpoxygenator requiring no blood for extended closed-chest circulatory support is available.

I am grateful to Lord Brock for his support and encouragement in this work. I would also like to thank D. Phelan, A. Smith, and G. Matthews for their enthusiastic technical assistance.

This study was supported in part by a grant from the British Heart Foundation.

\section{REFERENCES}

Gadboys, H. L., Jones, A. R., Slonim, R., Wisoff, B. G., and Litwak, R. S. (1963). The homologous blood syndrome. III. Influence of plasma, buffy coat and red cells in provoking its manifestations. Amer. J. Cardiol., 12, 194.

Henschel, E. O., Hamilton, L. H., and Rainbow, G. R. L. (1957). Catheterization of pulmonary veins and left heart chambers in the dog. J. appl. Physiol., 11, 319.

Johnston, J. B., Nield, J. M., Pritchard, G. R., and Hercus, V. M. (1965). Studies of left atrial pressure during cardioplegia pro- $C$ duced by profound hypothermia using the closed chest technique. Thorax, 20, 234.

Michenfelder, J. D., Kirklin, J. W., Uihlein, A., Svien, H. J., and MacCarty, C. S. (1964). Clinical experience with a closed-chest method of producing profound hypothermia and total circulatory arrest in neurosurgery. Ann. Surg., 159, 125.

Patterson, R. H., and Ray, B. S. (1962). Profound hypothermia for intracranial surgery: laboratory and clinical experiences with extracorporeal circulation by peripheral cannulation. Ibid., $\mathbf{1 5 6}$, 377 .

Proctor, E., and De Bono, A. H. (1965). A low priming volume oxygenator for bloodless priming in cardiopulmonary bypass. Thorax, 20, 540 .

_ and Kowalik, T. A. (1966). Circulatory support by pumpoxygenator in experimental ventricular fibrillation and acute left heart failure induced by coronary artery ligation. Cardiovascular Research, in press.

Ross, J., Jr., Gilbert, J. W., Sharp, E. H., and Morrow, A. G. (1958). Elective cardiac arrest during total body perfusion; the relationship of elevated intracardiac pressures during arrest to subsequent myocardial function and pathologic pulmonary changes. J. thorac. Surg., 36, 534.

Salisbury, P. F. Weil, P., and State, D. (1957). Factors influencing o collateral blood flow to the dog's lung. Circulat. Res., 5, 303.

- Bor, N., Lewin, R. J., and Rieben, P. A. (1959). Effects of partia and of total heart-lung bypass on the heart. J. appl. Physiol. 14, 458.

Schenk, W. G., Delin, N. A., Camp, F. A., McDonald, K. E., Pollock, L., Gage, A. A., and Chardack, W. M. (1964). Assisted circulation. Arch. Surg., 88, 327.

Spencer, F. C., Eiseman, B., Trinkle, J. K., and Rossi, N. P. (1965). \& Assisted circulation for cardiac failure following intracardiac surgery with cardiopulmonary bypass. J. thorac. cardiovasc. Surg., $\overline{\bar{O}}$ 49,56 .

Stuckey, J. H., Newman, M. M., Dennis, C., Berg, E. H., Goodman, S. E Fries, C. C. Karlson, K. E Blumenfeld, S. W Weitzner, S. W., Binder, L. S., and Winston, A. (1957). The use of the heartlung machine in selected cases of acute myocardial infarction. Surg. Forum, 8, 342.

Woodhall, B., Sealy, W. C., Hall, K. D., and Floyd, W. L. (1960). Craniotomy under conditions of quinidine-protected cardioplegia and profound hypothermia. Ann. Surg., 152, 37. 